\title{
Research on the Development Direction of National Audit in the Process of the Modernization of National Governance
}

\author{
Weiyu Chen, Lijin Zhang \\ Beijing Wuzi University, Beijing, China \\ Email: bjcwy@sina.com, 601516375@qq.com
}

Received 11 July 2016; accepted 1 August 2016; published 4 August 2016

Copyright (C) 2016 by authors and Scientific Research Publishing Inc.

This work is licensed under the Creative Commons Attribution International License (CC BY). http://creativecommons.org/licenses/by/4.0/

cC) (7) Open Access

\begin{abstract}
With the coordinated progress in advancing comprehensively deepening reform and the implementation for fully advancing the law-based governance of the country, the process of the modernization of national governance is comprehensively advancing, and great change has occurred in economic, social, political and some other fields. The development of national audit is facing new opportunities and challenges. In order to adapt to the new changes in the governance of the country, the national audit should break its restrictions about its theoretical framework, range, key, and methods, and make positive change and innovation development towards the direction of policy following audit, high pressure anti-corruption audit, and information-based audit.
\end{abstract}

\section{Keywords}

National Governance, National Audit, Development Direction

\section{National Governance and National Audit}

On July 2011, report "National governance and national audit” made by auditor-general Liu Jiayi makes us learn more about the nature of national audit. The national audit is essentially an "immune system" that has the function of preventing, revealing and resisting in the big system of national governance [1]. It is an important part of national governance, both of which are unique and complementary.

In 2013, the general objective for comprehensively deepening reform was formulated as "To improve and develop the socialist system with Chinese characteristics, and to promote national governance systems and governance capacity modernization” on the Third Plenary Session of the 18th CPC Central Committee [2]. The process of the modernization of national governance is just the process of toward modernization for the national 
governance system and the state governance capacity with mutual assistance and coordination.

On December 2015, The CPC Central Office and the General Office of the State Council issued the "Framework opinions on several major issues concerning the improvement of the audit system", it refers that until 2020 the Audit supervision mechanism adapting to the modernization of national governance system and governance capacity should be basically taken shape by improving the audit system.

Thus it can be seen, with the construction of socialist modernization stepped in a new stage of accelerating the system innovation and strengthening the construction of the whole system, national audit must also keep up with the pace of the modernization of national governance, promote reform and innovation actively, give full play to its role in the cornerstone of national governance, and provide fundamental guarantee for promoting the modernization of national governance system and governance capacity.

\section{Challenges to the State Audit in the Process of the Modernization of National Governance}

The concept of "national governance system and governance capacity modernization" was first proposed on the Third Plenary Session of the 18th CPC Central Committee, it is a great innovation of the idea of governing the country by the party. The fourth plenary session first request that "use legal frameworks and legal methods to promote reform", it is a great transformation of the strategy of governing the country by the party. With the coordinated progress in advancing comprehensively deepening reform and the implementation for fully advancing the law-based governance of the country, the process of the modernization of national governance is comprehensively advancing. These new trends will inevitably bring many challenges to the development of national audit, and the challenges mainly manifested in the following aspects:

(a) The basic theory of national audit needs to be improved

The status and function of the national audit in the National Governance is enough to cause people's high attention. In order to guide the practice of national audit, the theory of state audit must be developed, and the theory of national audit must be rooted in the theory of national governance. However, China is undergoing a transition period of high speed development, the country's governance is still in the exploratory stage and there are many problems left behind. Meanwhile, China insists on the road of socialism with Chinese characteristics, some mature theories in western countries cannot be generalized in our country. Therefore it is difficult to form perfect country governance theory that adapt to the national conditions [3]. Correspondingly, the innovation and perfection of the national audit theory becomes relatively difficult, which cannot play a very good guiding role for our country's national audit practice.

(b) Comprehensive governance leads to higher requirements for the national audit

The modernization of national governance is not only an important part of China's socialist modernization, but also a prerequisite and an important way to realize the socialist modernization. On February 2015, General secretary Xi Jinping formally explains the "four comprehensive" strategic layout, specifies the way to realize the modernization of national governance from the top-level design and the specific deployment, and Opens the great journey to accelerate the modernization of China's national governance.

The "four comprehensive" refers to comprehensively building moderately prosperous society, comprehensively deepening reform, comprehensively ruling the country by law and comprehensively running the Party strictly. From the goal, power, system, ability and other aspects the "four comprehensive" comprehensively planning out the unique patterns and unique paths through which the party and the people along the road of socialism with Chinese characteristics to achieve socialist modernization.

Promoting "four comprehensive" strategic layout in a coordinative way not only stipulates the goal of the modernization of national governance should be achieved, but also contains the specific measures to realize the modernization of national governance. It deeply reveals that national governance system is a logical and interlocking system, and only promote all constructions in coordinated manner and every construction cooperate with each other that can holistic system function be fully play and can effects of modernizing the national governance system and capabilities be fully achieved.

Correspondingly, the various means of national audit should also adapt to the tone of the overall coordination of national governance, and the system of national audit itself should also reform its own structure to match the "four comprehensive" strategic layout. This is an urgent requirement for the reform of the national audit system.

(c) Policy of high pressure anti-corruption puts pressure on the national audit

Since the 18th CPC National Congress, The Central Committee of the Communist of China (CPC) fight 
against corruption vigorously. Simultaneously, the fourth plenary session decides to establish a system of anticorruption mechanism, makes the whole political ecology change radically through build and run various mechanism that make people "Not dare, Not can, Not easy, Not want" to corrupt, and promotes high pressure anti-corruption and clean governance turn into the new normal within the framework of the rule of law.

To promote the construction of anti-corruption is the role that the national audit must play as a national governance "immune system" and it is determined by the nature of the national audit. It does not take auditors' will as the shift, nor it is a particular task attributed to a particular period or a particular government auditing agency. In fact, it is an important duty of all the state audit institutions that cannot escape. The national audit in China has its own advantages and important role in the governance of corruption, but it still has problems such as low independence, lack of accountability, lack of strength of the audit institutions. At present, the situation of high pressure anti-corruption undoubtedly added a lot of pressure to the national audit.

\section{(d) "National audit cloud" put forward technical challenges for the national audit}

At the 2015 national audit work conference, auditor-general Liu Jiayi indicates that in the "13th Five-Year" period, our country will strive to develop auditing information technology with big data as the core, build digital audit command platform, large data comprehensive analysis platform, integrated auditing platform, simulation laboratory and integrated service support system, set up national and provincial audit data system, form the "national audit cloud", realize the full coverage of the audit.

Along with the rapid development of information technology, the ability and level of national governance is also constantly upgrading, showing a high technology development trend [4]. Modern state governance should take the information and technology as the basic means, methods and tools. "Big data" is an important characterization of the information age, it has four fundamental characteristics: massive data size, fast and dynamic data transfer system, multi-type data model and low density data value. Based on these characteristics, it can integrate the information resources of the country's political, economic, cultural, social, ecological and other fields more effectively, and provide important data base and decision support for national governance.

Under the background of large data, to adapt to the comprehensive development of national governance, the national audit is also facing an important technical reform, the concept of "national audit cloud" arises at the historic moment. Our country is a big data country, but it is not a powerful data country. The goal to adapt to the development of information technology, form national audit cloud, and promote the realization of the full coverage of audit is undoubtedly a huge challenge for today's audit system.

\section{Some Suggestions on the Development of National Audit in the Process of the Modernization of National Governance}

Facing the challenges of national governance brought by the modernization of national governance, now national audit should take "giving full play to the audit's role of protection and supervision and achieving full coverage of the audit supervision" as its main responsibility just as "Opinions of the State Council on strengthening the work of auditing" call on, closely around the requirements of the modernization of national governance, and promote the modernization of national audit with target-oriented [5].

(a) Setting up the innovative framework of auditing primary theory which adapts to the process of modernization of national governance

On the basis of drawing lessons from foreign related theories, combining with the development course of our country's characteristics and the modernization of national governance, the industry should deeply summarize the experience of our country's national audit practice, conduct in-depth academic research on theoretical and practical issues about current national audit and national governance system and capacity during modernization process, effectively promote the national audit theory innovation and practice of close combination, put forward valuable research results and policy recommendations for China's national audit development and for the modernization of national governance systems and governance capacity, and eventually set up the most adaptive innovative framework of auditing primary theory to guide the work of the national audit practice.

(b) Adapting to the overall governance pattern of the state, widely carrying out policy tracking audit

Policy is the basic tool of national governance, the advantages and disadvantages of the implementation of policy decides the success or failure of the national governance. Currently, the scope of national governance covers all aspects of economic and social development, many important policy arrangements such as steady growth, inflation control, risk prevention, structural adjustment, reform promote have been ensuing introduced. 
Given this situation, in order to adapt to the current overall governance of the country, our government needs to carry out a wide range of major policy tracking audit.

On the one hand, we should focus on the supervision and inspection on the specific deployment, implementation progress and the actual effect about national policies and macro control measures implemented by all regions and departments, especially condition like major projects landing, key financial fund guarantee, and the implementation of streamlining government and delegating authorities; On the other hand, behaviors that go against the orders and prohibitions should be timely detection and correction. The "first one mile" and "the last mile" of the implementation of policy and measures should be knocked through and the "intermediate barrier" should be break out so that decrees can be ensured; In addition, we should also reflect good practices, experiences, new situations and new problems, help the policies take root and constantly improve; finally, we need to accelerate the establish of the long-effect mechanism of policy tracking audit, gradually explore a new path of policy tracking audit with Chinese characteristics, and provides guarantee to ensure the decrees be carried out as it is.

(c) Adapting to high pressure anti-corruption, strengthening the supervision and control to power

With the constantly deepening of the anti-corruption work and the gradually improving of anti-corruption mechanism and power restriction mechanism, the national audit needs to better fulfill its "duty" in anti-corruption. On the one hand, the supervision and control of the power operation should become more frequent. It requires us continuously to expand and strengthen the breadth, depth and intensity of economic accountability audit, make the government affairs known to the public and the decision, implementation, result more transparent, push forward the compliance and legalization for leaders and cadres to running their power. On the other hand, we must take anti-corruption initiate cheap as a long-term fundamental task. We must strive to "Hit the tiger", "beat the flies", improve the anti-corruption mechanism. We must expose, investigate and deal with violations of law and discipline, promote, build and develop the disciplinary mechanism that not dare to corrupt, the prevention mechanism that cannot to corrupt, the safeguard mechanism that not easy to corrupt, and the educational mechanism that make people don't want to corrupt, to be a pioneer and a sword of anti-corruption.

(d) Adapting to the high-tech governance, promoting the completion of the "national audit cloud" program

National governance is increasingly relying on high technology. It requires the national audit must keep pace with the times, innovate the audit techniques and methods to meet the requirements of the development and change of the objective environment of audit. In order to realize the "national audit cloud" plan, the national audit should focus on the construction of the audit information. On the one hand, according to the demand of audit work, national audit data system should be constructed rapidly to ensure a comprehensive collection of data. On the other hand, the active introduction of cloud computing, data mining, intelligent analysis and other advanced technologies can help us lay a good foundation for the use of data and build the data channel. In the end, the combination of data and auditing across the country and the gradually increasing of the comprehensive analysis of the data can help us promote networking audit, realize the full coverage of the audit, and finally form the "national audit cloud".

\section{Summary}

Under the new normal, great change has occurred in economic, social, political and some other fields. Due to the new trends and new changes of national governance, the national audit development is facing new opportunities and challenges. In order to adapt to the new changes in the governance of the country, the national audit should break its restrictions, and make positive change and innovation development towards the direction of policy following audit, high pressure anti-corruption audit, and information-based audit.

With the improvement of the theoretical framework, key point, scope and methods, national audit can better play its cornerstone role in national governance, help the realization of the national good governance and long-term stability, and promote the sustained, steady and healthy development of the economy and society.

\section{References}

[1] Liu, J.Y. (2012) The National Governance and National Audit. China Social Sciences, No. 6, 60-72.

[2] Sun, Y.J. (2013) Research on the Requirements and Path for National Audit to Perfect the National Governance. Audit Research, No. 6, 57-60. 
[3] Liu, J.Y. (2015) Research on the Audit Theory of Socialism with Chinese Characteristics. China Times Economic Press, Beijing.

[4] Yan, W.L. (2015) Research on Several Basic Problems of National Audit Theory-Based on the Perspective of Multiple Subjects. Audit and Economic Research, No. 1, 3-16.

[5] Zhang, L.M. and Xu, Z. (2014) Research on the Path for National Audit to Improve the National Governance from the Perspective of Audit Personnel. Audit Research, No. 1, 9-17.

\section{Submit or recommend next manuscript to SCIRP and we will provide best service for you:}

Accepting pre-submission inquiries through Email, Facebook, LinkedIn, Twitter, etc.

A wide selection of journals (inclusive of 9 subjects, more than 200 journals)

Providing 24-hour high-quality service

User-friendly online submission system

Fair and swift peer-review system

Efficient typesetting and proofreading procedure

Display of the result of downloads and visits, as well as the number of cited articles

Maximum dissemination of your research work

Submit your manuscript at: http://papersubmission.scirp.org/ 